\title{
Article
}

\section{Does Adhesive Layer Thickness and Tag Length Influence Short/Long-Term Bond Strength of Universal Adhesive Systems? An In-Vitro Study}

\author{
Naji Kharouf 1,2,*iD, Tarek Ashi ${ }^{3}$, Ammar Eid ${ }^{4}$, Levi Maguina ${ }^{2}$, Jihed Zghal ${ }^{5,6}$, Nairy Sekayan ${ }^{7}$, Rim Bourgi ${ }^{8} \mathbb{C D}_{\text {, }}$ \\ Louis Hardan $^{8}\left(\mathbb{D}\right.$, Salvatore Sauro ${ }^{9,10} \mathbb{D}$, Youssef Haikel ${ }^{1,2}$ and Davide Mancino ${ }^{1,2}$
}

check for

updates

Citation: Kharouf, N.; Ashi, T.; Eid, A.; Maguina, L.; Zghal, J.; Sekayan, N.; Bourgi, R.; Hardan, L.; Sauro, S.; Haikel, Y.; et al. Does Adhesive Layer Thickness and Tag Length Influence Short/Long-Term Bond Strength of Universal Adhesive Systems? An InVitro Study. Appl. Sci. 2021, 11, 2635. https://doi.org/10.3390/app11062635

Academic Editor: Ivana Miletić

Received: 1 March 2021

Accepted: 13 March 2021

Published: 16 March 2021

Publisher's Note: MDPI stays neutral with regard to jurisdictional claims in published maps and institutional affiliations.

Copyright: (C) 2021 by the authors. Licensee MDPI, Basel, Switzerland. This article is an open access article distributed under the terms and conditions of the Creative Commons Attribution (CC BY) license (https:// creativecommons.org/licenses/by/ $4.0 /)$.
1 Department of Endodontics, Faculty of Dental Medicine, Strasbourg University, 67000 Strasbourg, France; youssef.haikel@unistra.fr (Y.H.); davidemancino@icloud.com (D.M.)

2 Unité Mixte de Recherche 1121, Institut National de la Santé et de la Recherche Médicale, 11 rue Humann, CEDEX, 67085 Strasbourg, France; levimagui3@gmail.com

3 Private Practice, Zahnarztpraxis Ashi, Bahnhofstr 2, 09419 Thum, Germany; tarekachi@live.com

4 Department of Endodontics, Faculty of Dental Medicine, Damascus University, Damascus 0100, Syria; ammarendo89@gmail.com

5 ICube Laboratory, UMR 7357 CNRS, Mechanics Department, University of Strasbourg, 67000 Strasbourg, France; zghal@unistra.fr

6 Laboratoire Energetique Mecanique Electromagnetisme, University of Paris Ouest, 50 rue de Sèvres, 92410 Ville d'Avray, France

7 Department of Conservative Dentistry, Loma Linda University, 11092 Anderson St., Loma Linda, CA 92350, USA; nairysekayan@gmail.com

8 Department of Restorative Dentistry, Saint-Joseph University, Beirut 11072180, Lebanon; rim.bourgi@hotmail.com (R.B.); louis.hardan@usj.edu.lb (L.H.)

9 Dental Biomaterials and Minimally Invasive Dentistry, Department of Dentistry, Cardenal Herrera-CEU University, CEU Universities, C/Santiago Ramón y Cajal, s/n., Alfara del Patriarca, 46115 Valencia, Spain; salvatore.sauro@uch.ceu.es

10 Department of Therapeutic Dentistry, I.M. Sechenov First Moscow State Medical University, 119146 Moscow, Russia

* Correspondence: dentistenajikharouf@gmail.com; Tel.: +33-66752-2841

Abstract: (1) Background: This study investigated the effect of the adhesive layer thickness and the length of resin tags on dentin bond strength of five universal adhesives applied in self-etch mode. (2) Methods: One hundred and fifty extracted human third molars were used. Five different universal adhesives were applied in self-etch mode on the dentin surface. Half of the specimens were subjected to an aging procedure for six months. A shear bond strength (SBS) test was performed and the results were statistically analyzed with a $t$-test and one-way ANOVA test. Scanning electron microscopy (SEM) was executed to measure the adhesive layer thickness and tag depth. (3) Results: No statistical differences were found between the five adhesive systems after a $24 \mathrm{~h}$ storage period, regardless of layer thickness and tag depth $(p<0.05)$. After 6 months of aging in water at $37{ }^{\circ} \mathrm{C}$, Iperbond Max and Scotchbond Universal preserved the bond strength over time $(p<0.05)$, whilst the SBS of Iperbond Ultra, FuturaBond $\mathrm{M}+$, and Ibond Universal decreased significantly after the aging period. No relation was observed between the adhesive thickness or tags' length on SBS. (4) Conclusions: Within the limitation of this study, the stability over time of the bond strength of universal adhesives depends on their compositions regardless of the adhesive layer thickness and/or tags' length.

Keywords: universal adhesives; layer thickness; self-etch; dentin bonding; shear bond strength

\section{Introduction}

Universal dental adhesives have been developed to minimize the number of bottles and steps of application in order to make them more user-friendly and less time-consuming during their use in dental treatments [1-3]. Such multimode systems have showed a high 
bonding performance to enamel and dentin surfaces $[4,5]$ both when used in etch-and-rinse, in selective-etch, or self-etch mode [6].

These adhesives could be classified as strong $(\mathrm{pH}<1)$, mild $(\mathrm{pH}=2)$, or ultra-mild $(\mathrm{pH}>2.5)$, based on their acidity [3]. An etching step using orthophosphoric acid was recommended to apply such adhesives onto enamel surfaces [5]. However, bonding on dentinal substrate is more difficult due to its organic composition, dentin permeability, and the tubular structure [7]. Several studies demonstrated that modern universal adhesives applied in self-etch or etch-and-rinse mode can achieve substantial bonding to dentin [8,9].

One of the main advantages of the universal adhesives is that the clinician can select the application mode according to the clinical situation [10]. These adhesives may be used, not only on tooth substrates including resin composite, but also on different substrates, such as silica-based glass ceramics, metal alloys, and zirconia [6,11]. Several modern adhesives contain a functional acid monomer known as 10-methacryloyloxydecyl dihydrogen phosphate (10-MDP), which can interact and form a chemical bond with calcium ions in hydroxyapatite crystals $[4,12]$. However, different application procedures are required for those universal systems with different chemical compositions, in particular when containing an acidic functional monomer different from 10-MDP [13]. One of the main requirements of a dental adhesive is to create a resin-dentin bond in the oral cavity with appropriate durability over time due to minimal collagen degradation and monomers hydrolysis [2]. Long-term water storage at $37^{\circ} \mathrm{C}$ has been used in several studies to evaluate the durability of bonding performance through shear bond strength (SBS) or micro-tensile bond strength tests $[2,4,5]$. Some studies believe that the thickness and length of hybrid layer and resin tags, respectively, influence the bonding performance of adhesives at short and long time [14]; however, this aspect has not been yet clarified with modern universal bonding systems, so that it is necessary to study and publish the outcome of such an investigation.

Hence, the aim of the present study was to compare the bond strength of five universal adhesives applied onto the dentin surface at baseline $(24 \mathrm{~h})$ and after prolonged water storage (six months in $\mathrm{H}_{2} \mathrm{O}$ ). Moreover, it was investigated via scanning electron microscopy (SEM) whether the adhesive layer thickness and/or the length of the resin tags could influence the SBS after an aging period of six months. The first null hypothesis was that there would be no differences in bond strength between the five different universal adhesives after long-term water aging. The second null hypothesis was that the adhesive thickness and its resin infiltration into dentinal tubules would play no important role on the bond-strength durability.

\section{Materials and Methods}

\subsection{Sample Selection}

One hundred and fifty (150) human caries-free teeth, recently extracted for orthodontic reasons, were used in this study under a protocol approved by the Ethics committee (protocol no. 2018-89). The teeth were immersed in a 1\% sodium hypochlorite $(\mathrm{NaOCl})$ solution at $4{ }^{\circ} \mathrm{C}$ for $24 \mathrm{~h}$ and then stored in saline solution [15].

Two sections were made perpendicular to the longitudinal axis of the tooth crown using a saw microtome (Walter EBNER, Le Locle, Switzerland), to obtain dentin discs of $4 \mathrm{~mm}$ in thickness. The coronal surface was then hand-polished using a 320-grit silicon carbide paper (Escil, Chassieu, France) for $60 \mathrm{~s}$ continuous underwater irrigation [16].

The teeth were divided into five groups ( 30 teeth each) based on the universal adhesive systems used in this study. The adhesives were applied in self-etch mode following the manufacturer's protocol (Table 1). A silicone mold (3 $\mathrm{mm}$ in diameter) was used to make the resin composite build-ups on the occlusal dentin surface of the specimens using a resin composite Reflectys (ITENA Clinical, Paris, France), which was applied in three layers of $2 \mathrm{~mm}$ each. Each layer was light-cured for $40 \mathrm{~s}$ using an LED-curing system (Luxite Lampe LED, ITENA Clinical, Paris, France). Fifteen (50\%) specimens of each group were stored in 
distilled water at $37^{\circ} \mathrm{C}$ for $24 \mathrm{~h}$, while the other remaining part of the specimens for were stored 6 months.

Table 1. Adhesive system: chemical composition, application process, and manufacturing [3,17-19].

\begin{tabular}{|c|c|c|}
\hline Adhesive & Composition & Application \\
\hline $\begin{array}{l}\text { Iperbond Max-“IPM" } \\
\text { (Itena Clinical, Paris, } \\
\text { France) }\end{array}$ & $\begin{array}{c}\text { 10-MDP, 4-META, methacrylates, } \\
\text { photo-initiators, ethanol, water, } \\
\text { fumed silica }\end{array}$ & $\begin{array}{ll}\text { - } & \text { Apply }(20 \mathrm{~s}) . \\
- & \text { Wait until the solvent } \\
& \text { had completely } \\
& \text { vapored }(20 \mathrm{~s}) \\
\text { - } & \text { Dry }(5 \mathrm{~s}) \\
\text { - } & \text { Light cure (10 s). }\end{array}$ \\
\hline
\end{tabular}

\begin{tabular}{|c|c|c|}
\hline $\begin{array}{l}\text { Iperbond Ultra- } \\
\text { "IPU” (Itena Clinical, } \\
\text { Paris, France) }\end{array}$ & $\begin{array}{l}\text { Triethylenglycol dimetracrylate, } \\
\text { acrylate polyester urethane aliphatique, } \\
\text { bonding acelators, metacrylate } \\
\text { hydroxyethil, photo-starters, acetone, } \\
\text { ethanol, nanoparticules. }\end{array}$ & $\begin{array}{ll}- & \text { Apply + rub (20 s) } \\
- & \text { Dry (5 s) } \\
- & \text { Light cure (10 s). }\end{array}$ \\
\hline $\begin{array}{l}\text { Ibond Universal-“'IB" } \\
\text { (Kulzer, ZA } \\
\text { Courtaboeuf, France) }\end{array}$ & $\begin{array}{l}\text { Methacrylate monomers (UDMA), } \\
\text { Hydrophilic monomers (4-META), } \\
\text { glutaraldehyde, photo-initiators, } \\
\text { stabilizers, acetone, and water }\end{array}$ & $\begin{array}{ll}- & \text { Apply + rub (20 s) } \\
- & \text { Dry (5 s) } \\
- & \text { Light cure (10 s). }\end{array}$ \\
\hline $\begin{array}{l}\text { FuturaBond } \mathrm{M}+-“{ }^{\prime} \mathrm{FB}^{\prime} \\
\text { (Voco GmbH, } \\
\text { Cuxhaven, Germany) }\end{array}$ & $\begin{array}{c}\text { HEMA, BIS-GMA, ethanol, Acidic } \\
\text { adhesive monomer (10-MDP), UDMA, } \\
\text { catalyst ethanol, water, initiators, } \\
\text { and catalysts }\end{array}$ & $\begin{array}{ll}- & \text { Apply }+ \text { rub }(20 s) \\
- & \text { Dry }(5 \mathrm{~s}) \\
- & \text { Light cure }(10 \mathrm{~s})\end{array}$ \\
\hline $\begin{array}{l}\text { Scotchbond } \\
\text { Universal-“SU" (3M, } \\
\text { St. Paul, MN, USA) }\end{array}$ & $\begin{array}{l}\text { 10-MDP, HEMA, dimethacrylate resins, } \\
\text { Vitrebond copolymer, filler, ethanol, } \\
\text { water, initiators, silane }\end{array}$ & $\begin{array}{ll}- & \text { Apply + rub (20 s) } \\
- & \text { Dry (5s) } \\
- & \text { Light cure }(10 \mathrm{~s})\end{array}$ \\
\hline
\end{tabular}

\subsection{Shear Bond Strength Test (SBS)}

After each storage period, twelve specimens of each group were mounted to a testing machine (Instron 3345, "ISO/TS 11405 standard"). A constant crosshead speed of $0.5 \mathrm{~mm} /$ minute was used to submit the specimens to shear loading until fracture. By dividing the load at failure with the bonded surface area, the SBS (MPa) was calculated. After the SBS test, an optical numeric microscope (Keyence, Osaka, Japan) was used to investigate the failure mode in each specimen. A VHX-5000 software was used to calculate the percentage of each area at $50 \times$ magnification to define the type of fracture.

\subsection{Scanning Electron Microscopy (SEM)}

After each storage period, three samples of each group were sectioned along the sagittal plane, at the center of each cylinder using a saw microtome (Walter EBNER, Le Locle, Switzerland). Subsequently, the resin-dentin interfaces of the specimens were etched using 37\% phosphoric acid for $10 \mathrm{~s}$, rinsed for $10 \mathrm{~s}$ with distilled water, and immersed in a $2.5 \% \mathrm{NaOCl}$ solution for $3 \mathrm{~min}$ [20]. The specimens were finally rinsed with distilled water and dehydrated in a graded series of ethanol solutions. These were then mounted on aluminum SEM stubs, and sputter-coated with gold-palladium alloys (20/80) using a sputtering device (Hummer JR, Technics, CA, USA). The adhesive layer thickness and length of the resin tags (10 measurement for each section) were analyzed using a Quanta 250 FEG scanning electron microscope (FEI Company, Eindhoven, The Netherlands) functioning with a $10 \mathrm{kV}$ acceleration voltage of the electrons. 


\subsection{Statistical Analysis}

The $t$-test was applied using a Sigma plot (release 11.2, Systat Software, Inc., San Jose, CA, USA) to determine whether significant differences existed in the SBS values of each adhesive system between the two storage periods ( $24 \mathrm{~h}$ and 6 months). On the other hand, one-way analysis of variance (ANOVA) was used to determine whether significant differences existed in the SBS values of the five adhesive systems at $24 \mathrm{~h}$ and at 6 months. The Shapiro-Wilk test was used to verify the normality of data within all groups. However, normality was never verified. A one-way analysis of variance on ranks test was also used to compare the layer thickness or tag depths. In all tests, a statistical significance level of $\alpha=0.05$ was adopted.

\section{Results}

\subsection{Shear Bond Strength and Failure Modes}

Means and standard deviations, as well as the number of adhesive or mixed failures are depicted in Table 2. In general, higher SBS values were obtained for the tested adhesives after $24 \mathrm{~h}$ of a storage period compared to those obtained after 6 months $(t$-test, $p<0.05)$, except for Scotchbond Universal (SU) and Iperbond Max (IPM) $(p>0.05)$ (Figure 1).

Table 2. Shear bond strength means and standard deviations of the five adhesives at the two storage periods and the number of adhesive or mixed failures. FuturaBond M+- "FB", Scotchbond Universal-“SU”, Iperbond Max—“IPM", Iperbond Ultra—“IPU”, Ibond Universal_- IB". Different superscript letters indicate significant differences in rows, while different superscript numbers indicate significant differences in columns. Significance at $5 \%$ significant level $(p<0.05)$.

\begin{tabular}{cccccc}
\hline & FB & SU & IPM & IPU & IB \\
\hline $24 \mathrm{~h}$ & $\begin{array}{c}17.6 \pm 3.4 \\
\mathrm{a}, \mathrm{b}, 1\end{array}$ & $19.2 \pm 6.4^{\mathrm{a}, 1}$ & $18.6 \pm 4^{\mathrm{b}, 1}$ & $15.9 \pm 3.7^{\mathrm{b}, 1}$ & $15.3 \pm 3.3^{\mathrm{b}, 1}$ \\
\hline $\begin{array}{c}\text { Fracture } \\
\text { mode (Adhe- } \\
\text { sive/Mix) }\end{array}$ & $(13 / 2)$ & $(8 / 7)$ & $(10 / 5)$ & $(12 / 3)$ & $(12 / 3)$ \\
\hline 6 months & $14.7 \pm 4.1^{\mathrm{a}, 2}$ & $20 \pm 6.1^{\mathrm{b}, 1}$ & $\begin{array}{c}18.6 \pm 3.9 \\
\mathrm{a}, \mathrm{b}, 1\end{array}$ & $12.9 \pm 3.1^{\mathrm{a}, 2}$ & $12.9 \pm 2.3^{\mathrm{a}, 2}$ \\
\hline $\begin{array}{c}\text { Fracture } \\
\text { mode (Adhe- } \\
\text { sive/Mix) }\end{array}$ & $(12 / 3)$ & $(9 / 6)$ & $(11 / 4)$ & $(13 / 2)$ & $(13 / 2)$ \\
\hline
\end{tabular}

After $24 \mathrm{~h}$, no significant difference was found between the SBS values of the five tested adhesives (one-way ANOVA on ranks, $p>0.05$ ). Conversely, after six months of storage, no significant difference was found between SU, IPM, and FuturaBond M+ (FB) $(p>0.05)$. SU and IPM had higher SBS values than Iperbond Ultra (IPU) and Ibond Universal (IB) after prolonged storage $(p<0.05)$. Different failure modes were reported (Figure 2 and Table 2). 


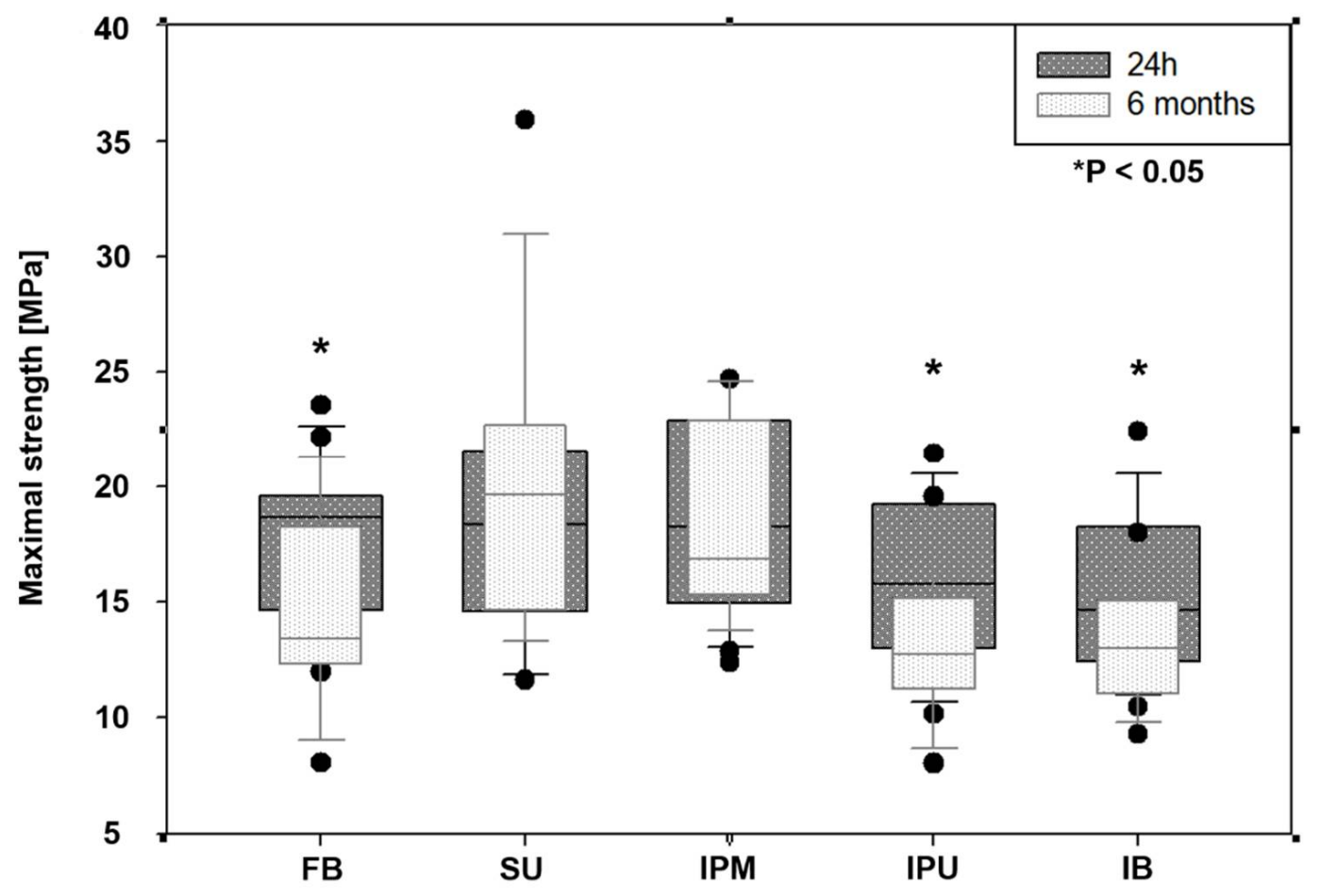

Figure 1. Evolution of the bond strength for the different universal adhesives at $24 \mathrm{~h}$ and 6 months. $\left({ }^{*} p<0.05\right)$. FuturaBond

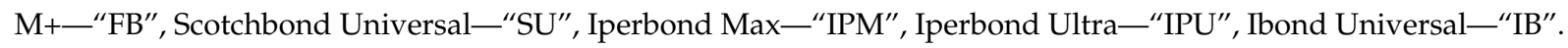

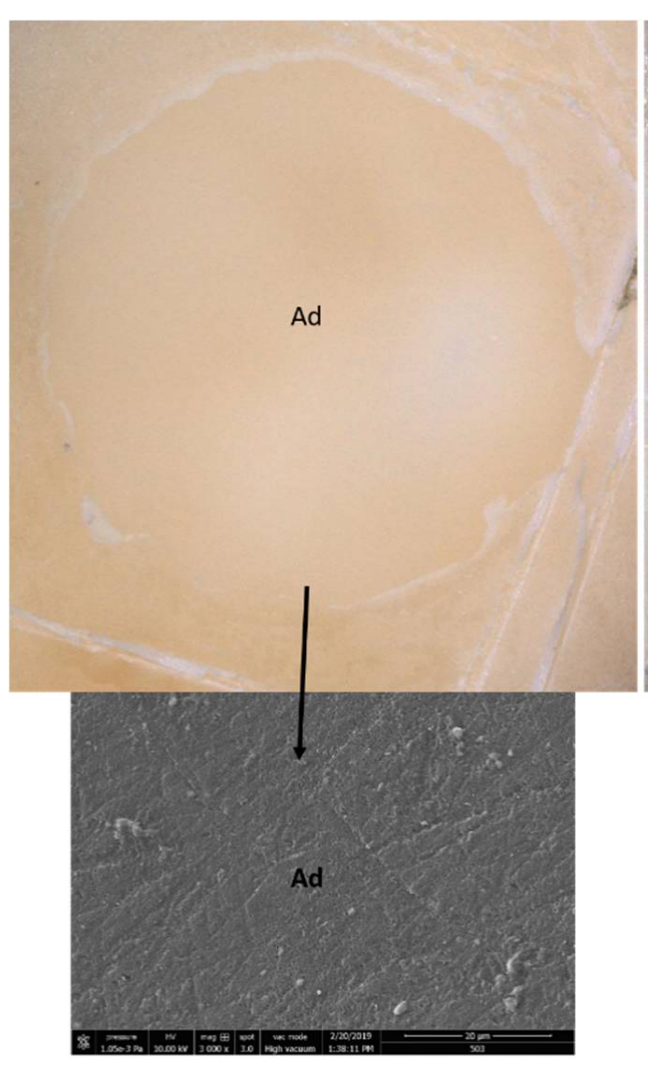

(a) Adhesive failure

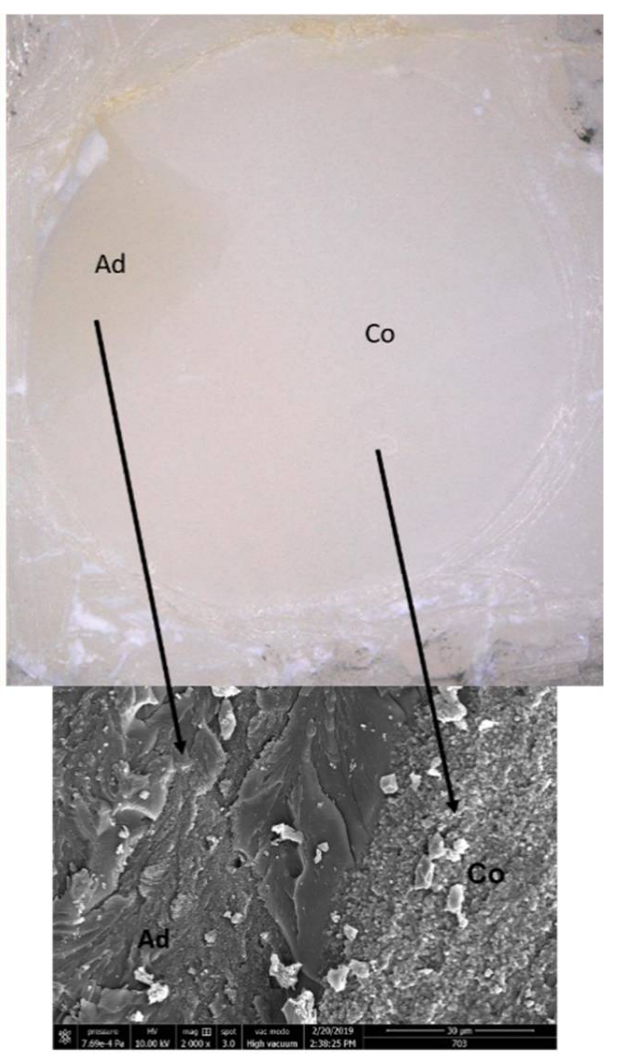

(b) Mixed failure

Figure 2. Representative images obtained with optical microscope and scanning electron microscopy (SEM). (a) Adhesive failure ( $\times 50$ magnification); (b) mixed failure $(\times 50$ magnification). Ad: adhesive; Co: Composite. 


\subsection{Scanning Electron Microscopy (SEM) Observation of Adhesive-Dentin Interface}

The mean thickness of the different adhesive layers ranged between 10 to $17 \mu \mathrm{m}$ was observed and measured under SEM for all adhesive systems (Figure 3, Table 3). SU and IB mean values were significantly higher than the mean values of IPM and FB $(p<0.05)$. Some specimens were created with IB fractured at the resin-dentin interface, probably due to SEM preparations and working pressure (Figure 3f).

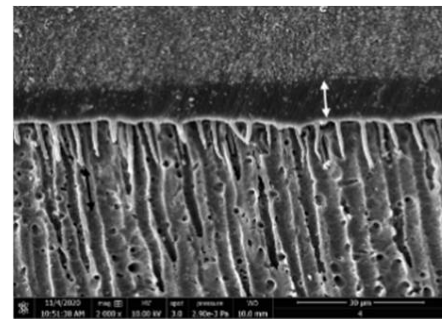

(a) FB

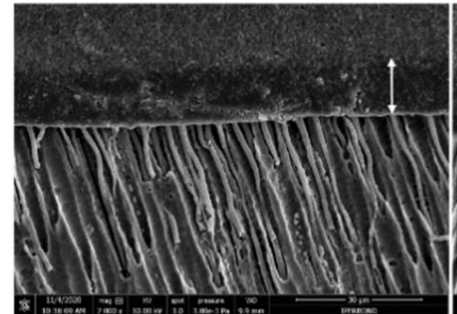

(d) IPU

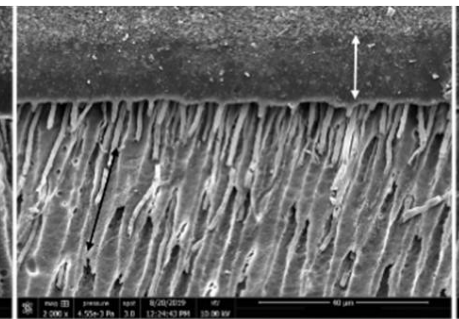

(b) SU

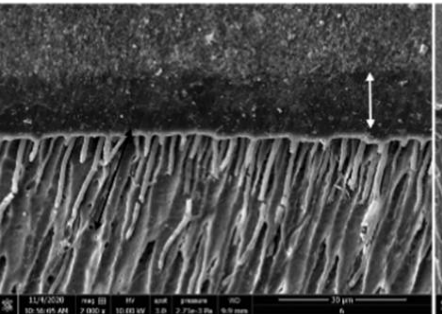

(e) IB

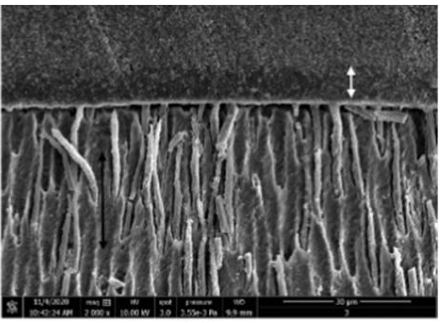

(c) IPM

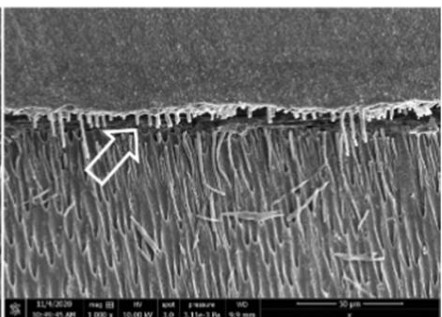

(f) SEM preparation artefact

Figure 3. Representative photos of scanning electron microscopy (A-E, x2000 magnification) demonstrating the adhesive layer thickness (white arrows) and tag depth (black arrows). (a) FuturaBond M+-"FB"; (b) Scotchbond Universal—“SU"; (c) Iperbond Max-"IPM"; (d) Iperbond Ultra-“IPU", (e) Ibond Universal- “IB". (f) SEM preparation artefact (x3000 magnification, white arrow).

Table 3. Adhesive layer thickness and tag depth values (means and standard deviations) of the five adhesives. FuturaBond M+- “FB", Scotchbond Universal—“SU”, Iperbond Max- "IPM", Iperbond Ultra-“IPU", Ibond Universal- "IB". Superscript letters $\left({ }^{\mathrm{a}-\mathrm{d}}\right)$ indicate significant differences at $5 \%$ significant level $(p<0.05)$.

\begin{tabular}{cccccc}
\hline & FB & SU & IPM & IPU & IB \\
\hline $\begin{array}{c}\text { Adhesive } \\
\text { thickness } \\
(\mu \mathrm{m})\end{array}$ & $11 \pm 4^{\mathrm{a}, \mathrm{c}}$ & $15 \pm 6^{\mathrm{a}, \mathrm{b}}$ & $10 \pm 4^{\mathrm{b}, \mathrm{d}}$ & $13 \pm 7$ & $17 \pm 9^{\mathrm{c}, \mathrm{d}}$ \\
\hline $\begin{array}{c}\text { Tag depth } \\
(\mu \mathrm{m})\end{array}$ & $4.6 \pm 2.2$ & $4.8 \pm 1.8$ & $5.6 \pm 2.1$ & $6.1 \pm 1.8$ & $5.6 \pm 2.3$ \\
\hline
\end{tabular}

No relation was observed between the SBS values and the thickness or the depth of resin-infiltration into dentinal tubules (Tables 2 and 3). SU and IB had the same infiltration depth and layer thickness but SU had higher SBS values at $24 \mathrm{~h}$ and 6 months. Therefore, thickness and tag length had no impact on the SBS values after the aging periods. One interesting finding was the observation of some voids in two IB six-month-aged samples (Figure 4). 


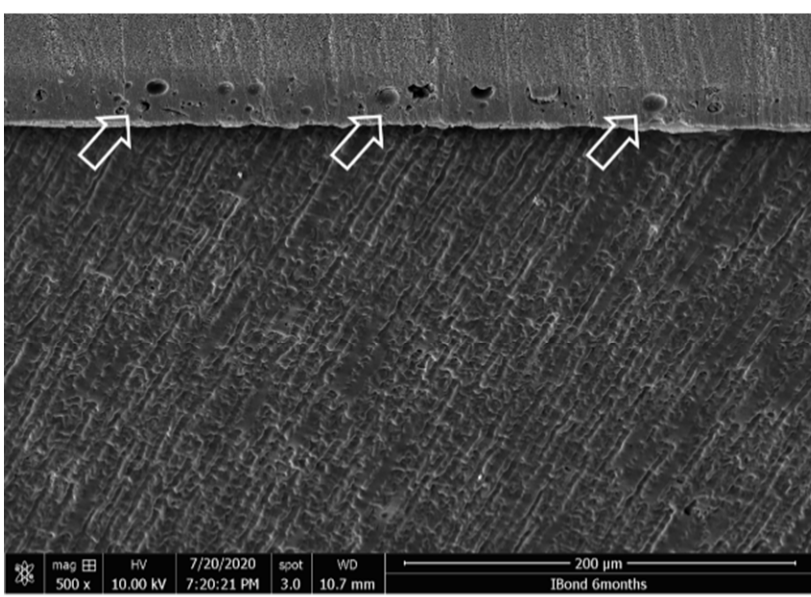

(a) voids in IB sample ( $x$ 500)

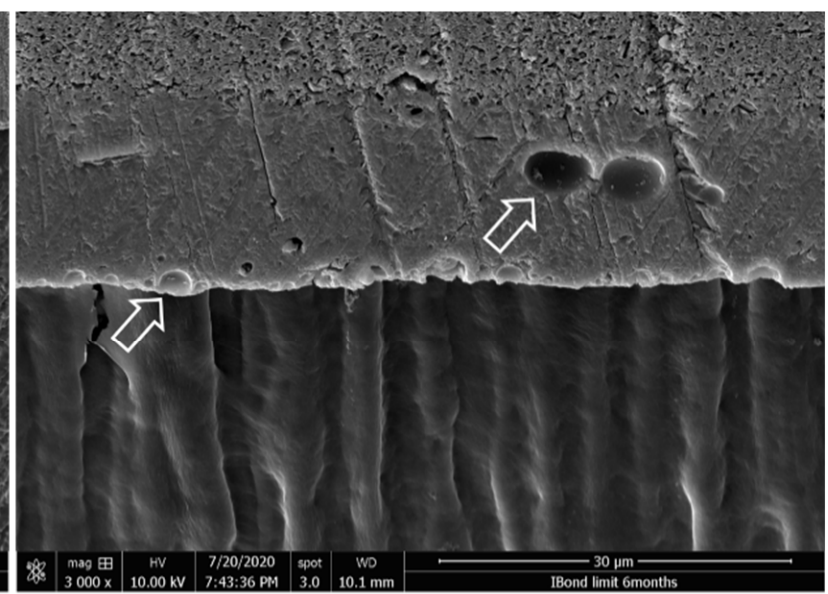

(b) voids in IB sample (x 3000)

Figure 4. Representative photos of scanning electron microscopy showed the voids into the IBond Universal adhesive layer (white arrows) after a 6-months water-storage period at $37^{\circ} \mathrm{C}$. (a): x500 magnification; (b): x3000 magnification.

\section{Discussion}

Dentin is a tissue characterized by a high organic content, which includes collagen fibers and odontoblasts in dentin tubules; these latter are filled with dentinal fluid [7,21]. It is well-known that the hydrolysis of collagen fibrils during storage in water could decrease the bond strength of the resin-dentin interface $[7,18,21]$. In this study, the bond strength for all the tested adhesive systems, which were applied following their manufacturers' instructions, was higher after $24 \mathrm{~h}$ of storage in water than after long-term storage. Immediately (after $24 \mathrm{~h}$ ) the SBS test showed no significant differences $(p>0.05)$ between the tested adhesives.

The adhesives SU and IPM preserved the bond strength values after a six-month storage period, whilst the SBS of IPU, IB, and FB decreased after long-term storage $(p<0.05)$. Therefore, the first hypothesis that there would be no difference between the tested adhesives in bond strength after long-term storage must be rejected. A possible explanation might be correlated to the different compositions of the tested materials, which influence the quality of the hybrid layer they create [2,22]. Indeed, the stability and durability of bond strength of IPM and SU could be in part attributed to the quality of 10-MDP used within their formulations. The formation of stable and insoluble nano-layered 10-MDP-calcium salts can significantly improve the bond strength and its durability over time [23]. Initial bond strength and its durability was shown to be important in the functional monomers that have more intense monomer-calcium formation than those creating lower monomer-calcium formation [23,24]. The results of our study are in accordance with those of Zhang et al. [25] and Saikaew et al. [2]; they reported that SU when it is applied in self-etch mode could preserve the bond strength after 12 months of an aging storage period. FB had lower bond strength after long storage, although it contains MDP; this may be due to the quality of the MDP used in the adhesive [26].

In this study, SEM was used to measure the thickness of the resin layer of the five tested adhesives applied onto dentin; the mean thickness ranged between 10 and $17 \mu \mathrm{m}$. SU and IB were significantly thicker than the other adhesives $(p<0.05)$. These findings might be explained and related to the adhesive fillers, which could play a crucial role in the flowability of such adhesives. However, no correlation was found between the thicknesses and SBS values of the tested adhesives. It has been reported that the bond strength of resin-dentin interface is independent from the thickness of hybrid and/or adhesive layer [27]. Conversely, the quality of hybrid layer is an important factor that can influence the dentin bond strength, whilst a thick adhesive layer does not offer any increase in bond strength [28]. 
All the adhesive systems used in this study created resin tags, which infiltrated several microns into dentinal tubules. Therefore, we hypothesized that all such adhesives can sufficiently dissolve the smear layer and allow the resin adhesive to enter into the tubules. However, the results of tag lengths were not significantly different $(p>0.05)$. These findings could be explained by the fact that all the tested adhesives have a mild $\mathrm{pH}$. Thus, the second hypothesis that the adhesive thickness and its resin infiltration into dentinal tubules would play no important role on the bond strength durability must also be rejected.

All the measures for the evaluation of the tag penetration were performed in correspondence of the center of the composite-cylinder in order to prevent the effect of tubules position (density and diameter). Tubules diameters and density increase from the dentinenamel junction to central dentin area [29].

Regarding the voids within the resin-adhesive layer of IB six-month-aged samples, it could be due probably to an incomplete evaporation of solvents and waters from the dentine interface [30]. Moreover, the gap observed in some specimens (Figure 3f) may be a consequence of specimen preparation, including sectioning procedures and drying steps [7]. The SEM is an effective analytical test to evaluate the resin-dentin interfaces, but with some limitations such as the artefacts (fracture or gap) at the dentin-adhesive interface caused by the different preparation steps [7]. However, one of the limitations of this study is that the bond strength of the tested adhesives was evaluated in vitro by the SBS test on flat dentin surfaces; this neglects an important clinical factor, which is the effect of C-factor [29]. In this study, the samples were tested using the SBS test because it is easier to prepare and no sectioning preparations (stick of $1 \mathrm{~mm}^{2}$ ) are required to perform the experiment. Beloica et al. [31] reported that the adhesive system is a significant factor for bond strength, regardless of the testing method used. However, other studies reported that the use of microtensile bond strength in this type of research is better than the SBS test [32]. Therefore, further in vitro and in vivo studies should be performed in the future to confirm the current preliminary results. Moreover, additional studies on different dentin-demineralization depths after adhesive application are recommended in order to analyze the quality of monomer-calcium bond to confirm these latter outcomes.

\section{Conclusions}

The current results indicate that adhesives with different chemical composition, the type, and the quality of the functional monomer within the materials' composition may influence the bonding performance in terms of degradation during prolonged storage in water, regardless of the adhesive layer thickness and length of the tags' penetration into the dentinal tubules.

Author Contributions: Conceptualization, D.M. and L.H.; methodology, N.K., L.M., J.Z. and T.A.; validation, L.H., S.S. and R.B.; formal analysis, J.Z.; investigation, L.M. and N.K.; resources, A.E.; data curation, J.Z. and L.M.; writing — original draft preparation, N.K., A.E., T.A. and N.S.; writingreview and editing, D.M., S.S. and Y.H.; supervision, D.M.; funding acquisition, Y.H. All authors have read and agreed to the published version of the manuscript.

Funding: This research received no external funding.

Institutional Review Board Statement: The protocol of this study was approved by the Ethics committee of Strasbourg University Hospital (protocol no. 2018-89).

Informed Consent Statement: Not applicable.

Data Availability Statement: Not applicable.

Acknowledgments: We acknowledge M. Hamdi Jmal and Platform IRIS/ICube, UMR 7357, FMTS, Université de Strasbourg for providing experimental setups for the mechanical characterizations.

Conflicts of Interest: The authors declare no conflict of interest. 


\section{References}

1. Frankenberger, R.; Kramer, N.; Petschelt, A. Technique sensitivity of dentin bonding: Effect of application mistakes on bond strength and marginal adaptation. Oper. Dent. 2000, 25, 324-330. [PubMed]

2. Saikaew, P.; Matsumoto, M.; Chowdhury, A.; Carvalho, R.-M.; Sano, H. Does Shortened Application Time Affect Long-Term Bond Strength of Universal Adhesives to Dentin. Oper. Dent. 2018, 43, 549-558. [CrossRef] [PubMed]

3. Pagano, S.; Lombardo, G.; Balloni, S.; Bodo, M.; Cianetti, S.; Barbati, A.; Montaseri, A.; Marinucci, L. Cytotoxicity of universal dental adhesive systems: Assessment in vitro assays on human gingival fibroblasts. Toxicol. In Vitro 2019, 60, 252-260. [CrossRef]

4. Kharouf, N.; Rapp, G.; Mancino, D.; Hemmerlé, J.; Haikel, Y.; Reitzer, F. Effect of etching the coronal dentin with the rubbing technique on the microtensile bond strength of a universal adhesive system. Dent. Med. Probl. 2019, 56, 343-348. [CrossRef]

5. Kharouf, N.; Mancino, D.; Rapp, G.; Zghal, J.; Arntz, Y.; Haikel, Y.; Reitzer, F. Does Etching of the Enamel with the Rubbing Technique Promote the Bond Strength of a Universal Adhesive System. J. Contemp. Dent. Pract. 2020, 21, 1117-1121. [CrossRef] [PubMed]

6. Imai, A.; Takamizawa, T.; Sai, K.; Tsujimoto, A.; Nojiri, K.; Endo, H.; Barkmeier, W.-W.; Latta, M.-A.; Miyazaki, M. Influence of application method on surface free-energy and bond strength of universal adhesive systems to enamel. Eur. J. Oral. Sci. 2017, 125, 385-395. [CrossRef] [PubMed]

7. Mortazavi, V.; Fathi, M.; Ataei, E.; Khodaeian, N.; Askari, N. Shear bond strengths and morphological evaluation of filled and unfilled adhesive interfaces to enamel and dentine. Int. J. Dent. 2012. [CrossRef]

8. Elkaffas, A.-A.; Hamama, H.-H.; Mahmoud, S.-H. Do universal adhesives promote bonding to dentin? A systematic review and meta-analysis. Restor. Dent. Endod. 2018, 43, e29. [CrossRef] [PubMed]

9. Yamauchi, K.; Tsujimoto, A.; Jurado, C.-A.; Shimatani, Y.; Nagura, Y.; Takamizawa, T.; Barkmeier, W.-W.; Latta, M.-A.; Miyazaki, M. Etch-and-rinse vs self-etch mode for dentin bonding effectiveness of universal adhesives. J. Oral. Sci. 2019, 61, 549-553. [CrossRef] [PubMed]

10. Hardan, L.; Bourgi, R.; Kharouf, N.; Mancino, D.; Zarow, M.; Jakubowicz, N.; Haikel, Y.; Cuevas-Suárez, C.-E. Bond Strength of Universal Adhesives to Dentin: A Systematic Review and Meta-Analysis. Polymers 2021, 13, 814. [CrossRef]

11. Irmak, Ö.; Yaman, B.-C.; Orhan, E.-O.; Ozer, F.; Blatz, M.-B. Effect of rubbing force magnitude on bond strength of universal adhesives applied in self-etch mode. Dent. Mater. J. 2018, 37, 139-145. [CrossRef] [PubMed]

12. Giannini, M.; Makishi, P.; Ayres, A.-P.; Vermelho, P.-M.; Fronza, B.-M.; Nikaido, T.; Tagami, J. Self-etch adhesive systems: A literature review. Braz. Dent. J. 2015, 26, 3-10. [CrossRef]

13. Fu, J.; Saikaew, P.; Kawano, S.; Carvalho, R.-M.; Hannig, M.; Sano, H.; Selimovic, D. Effect of air-blowing duration on the bond strength of current one-step adhesives to dentin. Dent. Mater. 2017, 33, 895-903. [CrossRef] [PubMed]

14. Anchieta, R.-B.; Oliveira, F.-G.; Sundfeld, R.-H.; Rahal, V.; Machado, L.-S.; Alexandre, R.-S.; Sundefeld, M.-L.; Rocha, E.-P. Analysis of hybrid layer thickness, resin tag length and their correlation with microtensile bond strength using a total etch adhesive to intact dentin. Acta. Odontol. Latinoam. 2011, 24, 272-278. [PubMed]

15. Mancino, D.; Kharouf, N.; Cabiddu, M.; Bukiet, F.; Haïkel, Y. Microscopic and chemical evaluation of the filling quality of five obturation techniques in oval-shaped root canals. Clin. Oral. Investig. 2020, 26, 1-9.

16. Kharouf, N.; Mancino, D.; Naji-Amrani, A.; Eid, A.; Haikel, Y.; Hemmerle, J. Effectiveness of Etching by Three Acids on the Morphological and Chemical Features of Dentin Tissue. J. Contemp. Dent. Pract. 2019, 20, 915-919. [CrossRef] [PubMed]

17. Chen, C.; Niu, L.N.; Xie, H.; Zhang, Z.Y.; Zhou, L.Q.; Jiao, K.; Chen, J.H.; Pashley, D.H.; Tay, F.R. Bonding of universal adhesives to dentine-Old wine in new bottles. J. Dent. 2015, 43, 525-536. [CrossRef]

18. Sauro, S.; Makeeva, I.; Faus-Matoses, V.; Foschi, F.; Giovarruscio, M.; Maciel Pires, P.; Martins Moura, M.E.; Almeida Neves, A.; Faus-Llácer, V. Effects of Ions-Releasing Restorative Materials on the Dentine Bonding Longevity of Modern Universal Adhesives after Load-Cycle and Prolonged Artificial Saliva Aging. Materials 2019, 12, 722. [CrossRef] [PubMed]

19. ITENA Clinical Products. Available online: https://www.itena-clinical.com/fr/adhesion/65-iperbond-max.html (accessed on 11 March 2021).

20. Kharouf, N.; Arntz, Y.; Eid, A.; Zghal, J.; Sauro, S.; Haikel, Y.; Mancino, D. Physicochemical and Antibacterial Properties of Novel, Premixed Calcium Silicate-Based Sealer Compared to Powder-Liquid Bioceramic Sealer. J. Clin. Med. 2020, 9, 3096. [CrossRef] [PubMed]

21. Kharouf, N.; Haikel, Y.; Ball, V. Polyphenols in Dental Applications. Bioengineering 2020, 7, 72. [CrossRef] [PubMed]

22. Ting, S.; Chowdhury, A.-A.; Pan, F.; Fu, J.; Sun, J.; Kakuda, S.; Hoshika, S.; Matsuda, Y.; Ikeda, T.; Nakaoki, Y.; et al. Effect of remaining dentin thickness on microtensile bond strength of current adhesive systems. Dent. Mater. J. 2015, 34, 181-188. [CrossRef] [PubMed]

23. Wang, R.; Shi, Y.; Li, T.; Pan, Y.; Cui, Y.; Xia, W. Adhesive interfacial characteristics and the related bonding performance of four self-etching adhesives with different functional monomers applied to dentin. J. Dent. 2017, 62, 72-80. [CrossRef] [PubMed]

24. Van Landuyt, K.-L.; Yoshida, Y.; Hirata, I.; Snauwaert, J.; De Munck, J.; Okazaki, M.; Suzuki, K.; Lambrechts, P.; Van Meerbeek, B. Influence of the chemical structure of functional monomers on their adhesive performance. J. Dent. Res. 2008, 87, 757-761. [CrossRef] [PubMed]

25. Zhang, Z.-Y.; Tian, F.-C.; Niu, L.-N.; Ochala, K.; Chen, C.; Fu, B.-P.; Wang, X.-Y.; Pashley, D.-H.; Tay, F.-R. Defying ageing: An expectation for dentine bonding with universal adhesives. J. Dent. 2016, 45, 43-52. [CrossRef] [PubMed] 
26. Yoshihara, K.; Nagaoka, N.; Okihara, T.; Kuroboshi, M.; Hayakawa, S.; Maruo, Y.; Nishigawa, G.; De Munck, J.; Yoshida, Y.; Van Meerbeek, B. Functional monomer impurity affects adhesive performance. Dent. Mater. 2015, 31, 1493-1501. [CrossRef]

27. Yoshikawa, T.; Sadr, A.; Tagami, J. Effects of C-factor on bond strength to floor and wall dentin. Dent. Mater. J. 2016, 35, 918-922. [CrossRef] [PubMed]

28. Gateva, N.; Kabaktchieva, R. Hybrid Layer Thickness in Primary and Permanent Teeth—A Comparison Between Total Etch Adhesives. J. Of Imab. 2012, 18, 191-199. [CrossRef]

29. Sinhoreti, M.A.C.; Soares, E.-F.; Abuna, G.-F.; Correr, L.; Sobrinho Roulet, J.-F.; Geraldeli, S. Microtensile Bond Strength of Adhesive Systems in Different Dentin Regions on a Class II Cavity Configuration. Braz. Dent. J. 2017, 28, 474-481. [CrossRef]

30. Sauro, S.; Pashley, D.-H.; Mannocci, F.; Tay, F.-R.; Pilecki, P.; Sherriff, M.; Watson, T.-F. Micropermeability of current self-etching and etch-and-rinse adhesives bonded to deep dentine: A comparison study using a double-staining/confocal microscopy technique. Eur. J. Oral. Sci. 2008, 116, 184-193. [CrossRef] [PubMed]

31. Beloica, M.; Goracci, C.; Carvalho, C.-A.; Radovic, I.; Margvelashvili, M.; Vulicevic, Z.-R.; Ferrari, M. Microtensile vs microshear bond strength of all-in-one adhesives to unground enamel. J. Adhes. Dent. 2010, 12, 427-433.

32. Sano, H.; Chowdhury, A.F.-M.A.; Saikaew, P.; Matsumoto, M.; Hoshika, S.; Yamauti, M. The microtensile bond strength test: Its historical background and application to bond testing. Jpn. Dent. Sci. Rev. 2020, 56, 24-31. [CrossRef] [PubMed] 